\title{
Advanced oxidation processes for environmental protection
}

\author{
Dionissios Mantzavinos • Ioannis Poulios • \\ Pilar Fernández-Ibañez $\cdot$ Sixto Malato
}

Received: 8 July 2014 / Accepted: 17 July 2014 / Published online: 11 September 2014

(C) Springer-Verlag Berlin Heidelberg 2014

Following Environmental Science \& Pollution Research commitment to the publication of high quality research articles on timely topics in the field of environmental monitoring and protection technologies, this is a special issue containing a selection of seventeen papers based on oral and poster communications from the third European Conference on Environmental Applications of Advanced Oxidation ProcessesEAAOP-3.

This time, the meeting was held in Almeria, Spain from the 28th to 30th of October 2013 and was organized under the auspice of Plataforma Solar de Almeria (www.psa.es), in collaboration with CIESOL (www.ciesol.es), a joint research center between the University of Almeria (UAL) and CIEMAT.

The objective of the conference was to bring together scientists, engineers, and other environmental professionals to present their findings and discuss future trends and directions concerning advanced oxidation processes (AOPs). The

Responsible editor: Philippe Garrigues

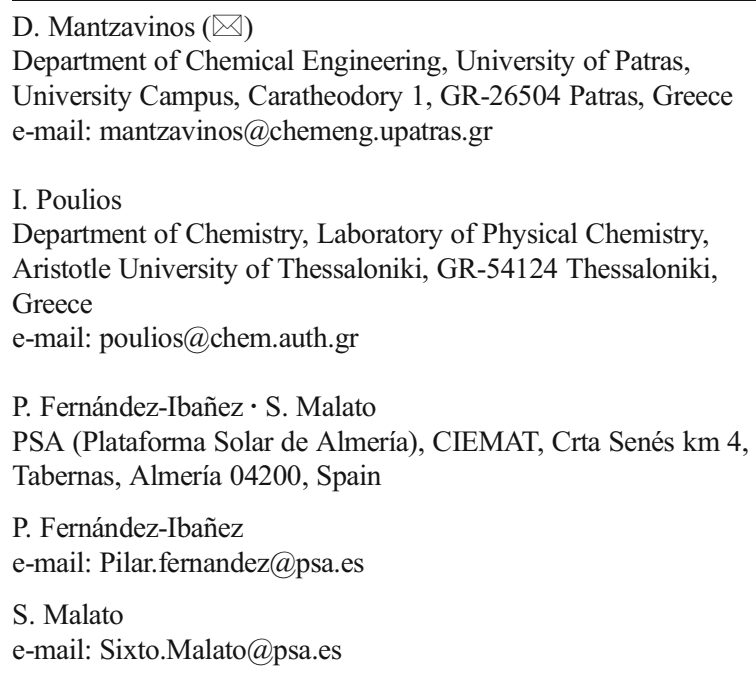

presentations focused on the scientific and technological advances of AOPs for the remediation of surface water, drinking water, groundwater, municipal, industrial and agro-industrial wastewater, and air and soil contaminated with various recalcitrant compounds, either alone or in conjunction with other processes.

AOPs are expanding their significance to a whole range of scientific applications under which participants from academia, research centers, and small and medium enterprises and industries are able to demonstrate new skills, report new achievements, and share relevant experiences and knowledge. Parallel to scientific significance is important to pass the message about the implications of such matters into everyday people's life, especially in what concerns clean water accessibility, in a way that governmental decision-makers and company shareholders can be brought to participate.

EAAOP meetings know how to rise to the occasion and the geographical bonds have naturally been broken. The more than 250 participants of the present edition came from 30 countries from different geographical areas including the EU (Austria, Cyprus, France, Germany, Greece, Ireland, Italy, Portugal, Slovenia, Spain, UK, etc), Mediterranean countries (Algeria, Egypt, Israel, Tunisia, Turkey), as well as Brazil, Colombia, India, Mexico, Russia, Serbia, Switzerland, and the USA. They produced a valuable body of information and knowledge, contained in more than 300 oral and poster contributions covering topics such as process fundamentals, reaction kinetics and mechanistic modeling, semiconductor photocatalysis and new materials, UV-based and radiation processes, Fenton and photo-Fenton processes, ozonation technologies, electrochemical processes, wet air oxidation processes, water and air disinfection, AOPs (and combined technologies) for water and soil treatment, AOPs for odor and VOC control, solar-driven applications, tertiary treatments, pilot scale and field applications, monitoring and control of process performance, and other new technology trends. 
The collection included in this special issue covers topics such as process combination (e.g., AOPs coupled either together or with separation or biological processes) for the efficient treatment of industrial effluents and emerging microcontaminants, experimental, and modeling studies in pilot-scale, compound parabolic collectors for solar photocatalysis, environmental chemistry and ecotoxicity of transformation by-products, and determination of reactive oxygen species, testing of materials with enhanced catalytic and photocatalytic properties. Classical processes still need improvement: ozonation and photo-Fenton and Fenton-like processes are also dealt with in this issue. All these clearly reflect the multi- and interdisciplinary approach needed to achieve higher levels of performance. It is quite rewarding to see the participation of researchers with different backgrounds working at the interface of science and engineering to understand and develop technologies for water and soil remediation.

This issue was only possible with the generous contribution of the authors and the journal's editors who handled the submissions. Sixto Malato wishes to thank the Spanish Ministry of Economy and Competitiveness financial support under the AQUAFOTOX Project (Reference: CTQ2012-38754C03-01) and the AQUASUN Project (Reference: CTM201129143-C03-03).

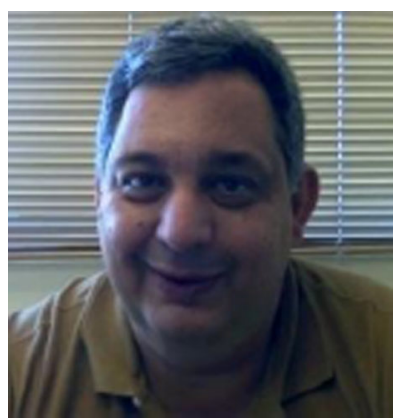

Dionissios Mantzavinos serves as a Professor of wastewater engineering in the Department of Chemical Engineering, University of Patras, Greece. He holds a Diploma (1991) in Chemical Engineering from Aristotle University of Thessaloniki, Greece, and M.S. (1993) and Ph.D. (1996) degrees in chemical engineering from Imperial College of Science, Technology, and Medicine, UK. After a short spell as a research fellow and lecturer at Edinburgh and Leeds Universities, respectively, he returned home to take up an academic position as an assistant, associate, and full professor in the Department of Environmental Engineering at the Technical University of Crete before his move to University of Patras. His research interests focus on water/wastewater treatment by physical, chemical, and biological processes, as well as on environmental catalysis. Particular emphasis is given to advanced oxidation technologies including heterogeneous and homogeneous photocatalysis, electrochemical oxidation, ultrasound radiation, wet air oxidation, ozonation, and various combinations of the above. Mantzavinos is involved in several academic and professional bodies and serves as executive editor to the Journal of Chemical Technology \& Biotechnology and associate editor to Water Research.

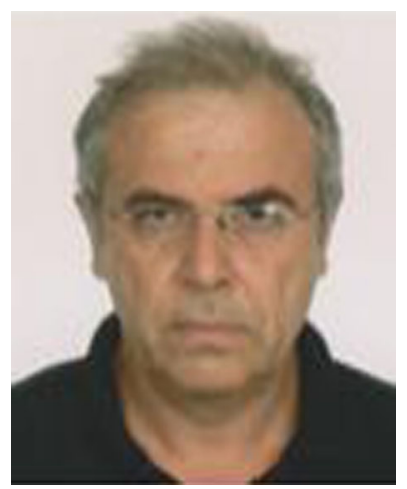

Ioannis Poulios was born in Serres, Greece in 1954. He received his Diploma in Chemical Engineering from the Technical University of Graz, Austria in 1979 and his Dr. Tech. degree from the same University in 1982. (Ph.D. thesis title: " $\mathrm{ZnO}$ photoeffects under galvanostatic and potentiostatic conditions"). $\mathrm{He}$ is currently a professor in the Laboratory of Physical Chemistry at the Department of Chemistry at the Aristotle University of Thessaloniki. His research interests include photoelectrochemistry of semiconductors, photoelectrochemical solar cells, heterogeneous and homogeneous photocatalysis, solar detoxification and disinfection of wastewaters, drinking water and air. His most recent research efforts are focused on hydrogen production by using photoelectrochemical/photosynthetic processes. He was an organizer of three International Conferences on the Environmental Applications of the Advanced Oxidation Processes, he is acting as a referee for most of the journals in the area of environmental science, and was a guest editor of four special issues. Prof. I. Poulios was in the period 2009-2011 director of the Division Physical, Analytical and Environmental Chemistry of the Chemistry Department and currently director of the Physical Chemistry Laboratory.

Full current CV with publication lists can be found at http:// photocatalysisgroup.web.auth.gr

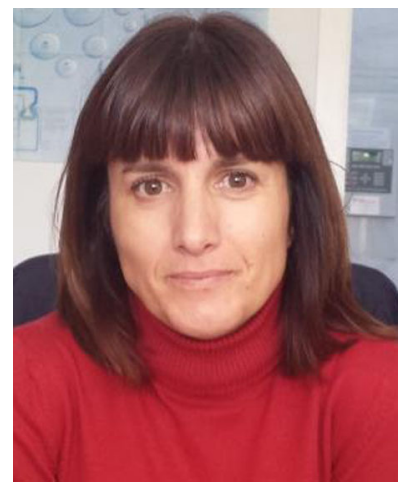

Dr. Pilar Fernández Ibáñez is senior researcher in the Plataforma Solar de Almería in the Centro de Investigaciones Energéticas Medioambientales y Tecnológicas and head of the group of Solar Treatment of Water. She obtained her $\mathrm{PhD}$ in Physics from the University of Granada (2004). Since then, she has been working in water treatment and disinfection using solar energy. She was involved in a number of projects, coauthored 4 books and 16 book chapters, 80 publications in indexed journals, 2 patents, and graduated $3 \mathrm{PhD}$ students. She has been awarded the status of Visiting Professor at the University of Ulster (2012). 


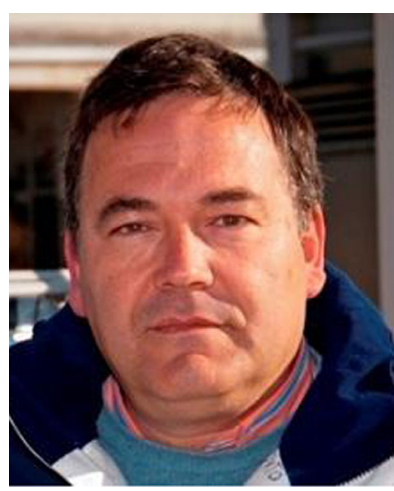

Dr. Malato was born on May 10, 1964, and has a Ph.D. in Chemical Engineering. $\mathrm{He}$ is the director of Plataforma Solar de Almeria (www.psa.es) and Joint Research Center (Univ. Almería-CIEMAT) of $\mathrm{R} \& \mathrm{D}$ in Solar Energy (CIESOL). http:// www.ciesol.es. He has 25 years of experience working at different sectors. He works at the Plataforma Solar de Almeria (PSA-CIEMAT) in all the projects linked to solar water treatment. Concretely, he has been involved in $16 \mathrm{EU}$ and 20 National related to the development of solar wastewater treatment technologies and has been involved in the design and construction of all the experimental pilot plants for solar detoxification of industrial waste water in Europe. He is the author of one book and co-author of 16 books as well as 56 chapters in others. He has also co-authored more than 190 publications in indexed international journals and four patents. He has directed $11 \mathrm{PhD}$ thesis. He is also the assistant editor of Environmental Chemistry Letters (Ed. Spinger) and Journal of Advanced Oxidation Technologies (Sci.\& Technol. Network, Inc.). Dr. Malato is a member of the editorial board of Catalysis Today (Elsevier) and Photochemical and Photobiological Sciences (RSC Publishing). He has an h-index (http://www.scopus.com, December 2013) of 51. He has received awards from The Jury's Grand Prix of "European Grand Prix for Innovation Awards" (11 December 2004, Mónaco; http://www.european-grandprix.com/ index en.htm) and Jaime I Price in Environmental Protection, 2011 (Most important in science in Spain; http://www.fvea.es/ medioambiente.html). 